\title{
Physical Origin of the Fine-Particle Problem in Blasting Fragmentation
}

\author{
A. Iravani, ${ }^{1, *}$ J. A. Åström, ${ }^{2}$ and F. Ouchterlony ${ }^{1}$ \\ ${ }^{1}$ Department of Mineral Resources Engineering, Montanuniversitaet Leoben, A8700 Leoben, Austria \\ ${ }^{2}$ CSC-IT Center for Science, P.O. Box 405, FIN-02101 Esbo, Finland
}

(Received 7 March 2018; revised manuscript received 23 May 2018; published 4 September 2018)

\begin{abstract}
Blasting with explosives and crushing with mills are two major processes for extracting ore minerals. Longstanding problems with these processes are "fines" production in blasting and the related energy consumption of mills. Here, we demonstrate, using numerical simulations and comparison with experiments, that both problems emerge from two universal mechanisms: unstable tensile-crack propagation and compressive impact crushing. These lead to a universal mass-passing-fraction function in sieving. Crushing is limited to, and produces almost all the fines, and thereby inherently consumes a lot of fracture energy. Tensile cracks also produce fines, but the majority of the mass is confined in larger fragments. The key to resolving the fines and energy problem thus lies in minimizing crushing while inducing enough tensile load to reach the breakage threshold.
\end{abstract}

DOI: 10.1103/PhysRevApplied.10.034001

\section{INTRODUCTION}

The extraction of metals from ore minerals is one of the most important industrial processes. In a schematic sense, the initial phase of mineral extraction is the blasting of rock to break it, and then to crush large fragments in mills to produce pieces of desired sizes. A similar procedure is used in the production of construction aggregates for civil-engineering purposes. The interplay between blasting and crushing-milling fragments is quite complex [1]. Two longstanding problems exist within these processes: (1) the production of "fines" or dust in the blasting process, which is an economic waste and an environmental hazard $[2,3]$; and (2) the huge energy consumption of grinders and mills run by electric motors [4].

The energy consumption problem is, at least partly, a consequence of fines produced in mills. The creation of fines requires a lot of energy as the total created fracture surface grows large. Consequently, the two problems can be condensed into a "fines" problem. A better understanding of the origin of fines could help eliminate these problems at an initial stage and improve the blasting and crushing practices.

There are existing theories on the source of fine particles, such as the crushed-zone model (CZM), which

\footnotetext{
*armin.iravani@unileoben.ac.at
}

Published by the American Physical Society under the terms of the Creative Commons Attribution 4.0 International license. Further distribution of this work must maintain attribution to the author(s) and the published article's title, journal citation, and DOI. assumes that fines originate from an annular compressive failure around the blasthole [5] consisting of two nonoverlapping Rosin-Rammler components, one for the coarse material and one for the fine material of the crushed zone. The CZM may be interpreted so that the fragment size is almost (solely) defined by the distance to a blasthole. The two-component model (TCM) [6], in which the connection between distance and size is more diffuse, has defined the shear failure along the in situ joints and blastinduced cracks as the other source of fines [7]. Additions to the CZM by Onederra et al. [8] have assumed that the fine particles originate from a circular compressive failure zone around the borehole, as well as from crushed and/or sheared material bounded by major blast-induced radial cracks, which are assumed to be evenly distributed around a blasthole, planar, and also to continue along the length of the explosive charge. This constitutes the star-shaped crushed-zone model [9].

The blast cylinders of Svahn [10] are ideal test models to analyze the star-shaped model. The cylinders $(\oslash 300 \mathrm{~mm}$ $\times$ length $600 \mathrm{~mm}$ ), whose material is categorized using three different colors in the radial direction, i.e., $\oslash_{\text {outer }}=$ 120,200 , and $300 \mathrm{~mm}$ for black, yellow, and green, are blasted. The colored layers are concentric and centrally charged [see Fig. 2(a) in the Supplemental Material [9]]. The fragment-size distribution (FSD) results illustrate a whole range of fragment sizes for the core layer, with an identical general character to that of the outer layers. The results illustrated no tendency either for the core material to consist only of fines or for the outer layers to contain no fines. Both regions (black, yellow + green) produce the whole range of fragment sizes. The black core contains 
even less fragments that are smaller than $2 \mathrm{~mm}$ fines in absolute terms than the outer layers, bearing in mind that there is no crushing inside the two outer layers [see Fig. 2(b) in the Supplemental Material [9] ]. From the analysis of the star-shaped model, one realizes that the relative amount of fines will always decrease with each successive layer of materials. However, the absolute amount of fines generated in the outermost layer is almost double that of the middle layer. This would indicate that the fine particles are generated by mechanisms other than crushing in the outermost layer.

When blasting cylinders of a given size with decreasing amounts of explosives, a critical charge size is reached. At this stage, the cylinder barely falls apart into a few large blocks plus small amounts of very fine materials $[11,12]$. In the cases referred to, the crushed zone and fragment collisions do not exist. Åström [13] has addressed this issue and declared the unstable rapidly propagating cracks as a source of fines, the physical origin of which is rooted in an intrinsic scale-invariant branching-merging process. Yet another plausible theory is that the fines are generated by a mechanism involving dynamic crack branching and merging $[14,15]$.

The fines problem can be characterized and quantified by the so-called mass-passing-fraction (MPF) function, which has characteristics that are universal for both blasting and mill crushing under different loads [16]. In the mining and construction industries, which handle vast masses of rock and ore each year, productivity is related to mass moved and crushed or milled (comminution), not to numbers of fragments and/or mass for a given size. Aggregate products are, for example, often further defined in terms of their MPF; hence the industries' preoccupation with the MPF. The MPF( $r)$ is defined as the fraction of mass for a collection of fragments that pass through sieves with different mesh sizes $r$. That is, for a mesh size $r=0$, $\operatorname{MPF}(r)=0.0$, and $\operatorname{MPF}\left(r>r_{\text {max }}\right)=1.0$ or $100 \%$, where $r_{\text {max }}$ is approximately the largest possible fragment.

In most applications, oversize fragments that are too large to handle are a larger liability than an excessive amount of fines but respirable dust, slow leaching and ore losses, etc., are important problems associated with fines. An ongoing project [17] is trying to define the role of crack branching and merging in the generation of fines by HSV recording and modeling of dynamic cracks $[11,18]$ (for the expected use of the results beyond rock-fracture research, see Sec. II in the Supplemental Material [9]).

\section{THE MODEL}

In this paper, we employ a discrete-element code (HiDEM) to simulate blasting experiments of magnetic mortar cylinders. The experiments were conducted by Johansson [12] as a set of laboratory blasting fragmentations of magnetic mortar cylinders $(\oslash 140 \mathrm{~mm} \times$ length
$280 \mathrm{~mm}$ ) with PETN (pentaerythritol tetranitrate) cord, with charge concentrations varying from $3,5,10$, and 20 to $40 \mathrm{~g} / \mathrm{m}$. Here, we use data from two set of blasting experiments with different confining conditions, i.e., loose and stiff confinement. The fragment data are collected as masspassing fractions in sieving with mesh sizes ranging from 0.063 to $90 \mathrm{~mm}$.

In the HiDEM code, a brittle material is discretized as a dense-packed face-centered cubic (fcc) lattice of inelastic spheres connected by breakable beams. The model is described in detail in Refs $[13,19]$. We model cylinders with material properties that mimic those of magnetic mortar, and use a time-dependent pressure pulse that crudely replicates the blasting process [11]. That is, we apply an initial pressure pulse with a value $P_{\text {peak }}$ proportional to the charge density that lasts for about a microsecond, and that travels through the sample with a velocity of detonation (VOD $\sim 6000 \mathrm{~m} / \mathrm{s})$. There is also a post-peak pressure pulse $\left(P_{\text {post }} \sim 0.02 P_{\text {peak }}\right)$ that lasts for $30 \mu \mathrm{s}$, and that acts on a larger region than the initial pulse. The true blasting process is highly complex [20] and cannot be modeled in any detail here. Regardless, it seems that applying the pressure-pulse scheme with minor adjustments of the post-peak pressure $(0.4-6 \%$ of the peak pressure) to mimic various experimental boundary conditions is enough for the numerical model to replicate the crack patterns and MPFs of the experiments. That is, we use the slightly larger $P_{\text {post }}$ for looser confinement and vice versa. This is simply an observation of how the model works. We are not aware of the physical origin of this behavior.

Before examining the simulation and experimental results, we construct a theoretical estimate of $\operatorname{MPF}(r)$. The blasting experiments create a compressive shock wave traveling outward in the radial direction. As a cylinder expands outward, it will induce tension in the tangential direction. This immediately indicates that the blasting process will generate both tensile fracture and crushing.

Tensile fracture means crack propagation. Propagating cracks easily become unstable and branch. Crack branches easily merge again to form fragments, which means that propagating cracks leave behind not smooth crack surfaces but fragment-filled fracture zones of finite widths. This process is inherently universal and leads to a characteristic FSD $[13,21]$. The number of fragments, $n_{\mathrm{bm}}(s)$, of size $s$ in an interval $d s$ can be written as $n_{\mathrm{bm}}(s) d s=$ $C_{2} s^{-\alpha} \exp \left(-s / C_{3}\right) d s$, with $\alpha=(2 D-1) / D$, where $D$ is dimension (i.e., $D=1,2,3$ for rods, membranes, and bulk objects, respectively) and $C_{2}, C_{3}$ are nonuniversal constants $[13,21,22]$. The dimensionless size $s$ is measured as the number of grains composing a fragment (i.e., DEM particles or mortar grains). The power-law part of the FSD originates from branching and merging cracks, while the exponential part introduces a cut-off at a finite width of the fracture zone at which fragmentation locally runs out 
of energy. In nature, fragmentation processes of this kind range in size from stellar fragments [23] through icebergs [24] and meteorites [25] to fault gouge [26] and dust [27].

Crushing contains some induced tensile fracturing but it - and especially grinding - are essentially compressiveshear fracture and they are typically processes of continued fragmentation following an initial crack-propagation phase. Such a process essentially modifies the FSD. When tensile cracks have opened up, small-size debris-filled fracture zones are formed. In compressive shear, this debris will be crushed into decreasingly smaller fragments by grinding and compaction. Grinding compaction can, in a schematic fashion, be viewed as a hierarchical process in which ever-smaller fragments are broken to fill pore space that opens up in continuous shear deformation $[28,29]$. Such a process has a power-law FSD of the form $n_{\text {crush }}(s) d s=C_{1} s^{-\beta} d s$ [13], where $C_{1}$ is a constant and $\beta \sim 1.8-3.5$ for $D=3$, depending on the degree of grinding and/or crushing. The lower bound for $\beta$ is determined by $\beta>\alpha$, while the upper bound of 3.5 seems to be more of a practical nature than a hard theoretical limit. A value of $\beta \approx 3.5$ means a very high degree of grinding.

For low blasting loads, the fragments formed by branching and merging in fracture zones amount to just a small fraction of the total mass of a cylinder. Large more or less undamaged "boulders" remain between the formed fracture zones. Note that in our case "boulder" does not mean oversize with respect to the available equipment but merely fragments that are very large compared to the original cylinder. At low loads, the mass fraction of these boulders easily dominates the MPF. For increasing loads, the mass fraction of the boulders decreases and eventually vanishes (cf., Fig. 1). As a first approximation, crack paths far enough from each other for boulders to be formed may be considered as independent. This will result in a Poisson process, and an essentially exponential FSD for boulders [30].

If $n(s)$ describes the number density of fragments with $s$ grains, the FSD, or the number of fragments in a size interval $d s$, can then be written as follows:

$$
n(s) d s=C_{1} s^{-\beta} d s+C_{2} s^{-\alpha} \exp \left(-\frac{s}{C_{3}}\right) d s+n_{b}(s) d s,
$$

where the value for $\beta$ can be determined from a grinding experiment which is discussed later, (see Sec. III descriptions regarding Fig. 4), $C_{3}$ determines the typical size of the boulders, $n_{b}(s) \sim \exp \left(-s / s_{b}\right)$ is the size distribution for the boulders, and $s_{b}$ is the characteristic size of a boulder, governed by the density of induced tensile cracks. Sometimes a large-size cut-off to the crushing power law also appears, which can be approximated by multiplying that first term on the right-hand side by another exponential function.
With the transformation $d s \propto r^{2} d r$ for $D=3$, the $\operatorname{MPF}(r) \sim\left(1 / M_{0}\right) \int_{r_{\text {grain }}}^{r} r^{3} n(r) r^{2} d r$ can be approximated for fragments smaller than boulders, i.e., for $r \lesssim r_{\text {grain }} C_{3}^{1 / 3}$, using the function

$$
\operatorname{MPF}(r)=f_{\text {cr }}\left(1.0-\left(\frac{r}{r_{\text {grain }}}\right)^{-3 \beta+6}\right)+f_{\mathrm{bm}}\left(\frac{r}{r_{\text {max }}}\right)^{-3 \alpha+6},
$$

where

$$
\begin{gathered}
f_{\mathrm{cr}}=\frac{m_{\text {grain }}}{M_{0}} \frac{-3 C_{1}}{-3 \beta+6}, \\
f_{\mathrm{bm}}=\frac{m_{\text {grain }}}{M_{0}} \frac{3 C_{2} r_{\max }^{-3 \alpha+6}}{\left(r_{\text {grain }}^{-3 \alpha+6}\right)(-3 \alpha+6)},
\end{gathered}
$$

in which $M_{0}$ is the total mass; $r_{\text {grain }}$ is the grain size of the material; and, for $D=3$, the value of $3 \alpha+6$ is equal to 1 and thus the first part on the right-hand side of Eq. (2) is the empirical Gates-Gaudin-Schuhmann (GGS) [31] or a simple power-law distribution with exponent $m=1$, and the second part represents the characteristic shape of MPFs for the crushed fines. The parameters $f_{\text {bm }}, f_{\text {cr }}$ thus determine the mass fractions of fragments formed in the branchingmerging and crushing processes, respectively. The ratio $f_{\text {cr }} / f_{\mathrm{bm}} \sim C_{1} r_{\text {grain }} / C_{2} r_{\text {max }}$ determines the ratio of crushing to branching-merging fragments. This could be used as such to be the representative measure for the optimization of blasting and the corresponding fragmentation. Finally, the mass fraction of the boulders, absent from Eq. (2), can then be written as $1.0-\left(f_{\mathrm{bm}}+f_{\mathrm{cr}}\right)$.

In the general case, the MPF can be written as a sum of two incomplete Gamma functions and, if $n_{b}(r)$ is assumed to be a Poisson process, an exponential function.

\section{RESULTS AND DISCUSSION}

Figure 2(a) shows an experimental $\operatorname{MPF}(r)$ for $P_{\text {peak }}=$ $160 \mathrm{MPa}$ and $P_{\text {post }}=0.06 P_{\text {peak }}$. The experimental data can be fitted almost perfectly by the numerically integrated theoretical $\operatorname{MPF}(r)$ from the general case, except for the very smallest fragments. The theoretical function is obtained by an integral with an assumed constant material grain size $r_{\text {grain }}$. For real materials, $r_{\text {grain }}$ is not a constant, and the small-size limit of the MPF $(r)$ will reflect this grain-size distribution. For simplicity, we may assume that the mortar grains have a Gaussian size distribution and, as is evident in Fig. 2(a), this fits the experimental data very well.

For comparison, a straight line that represents the $\operatorname{GGS}(m=1)$ function is also displayed in Fig. 2(a) to demonstrate the range in which branching-merging fragments dominate the MPF. Before reaching 100\%, the 

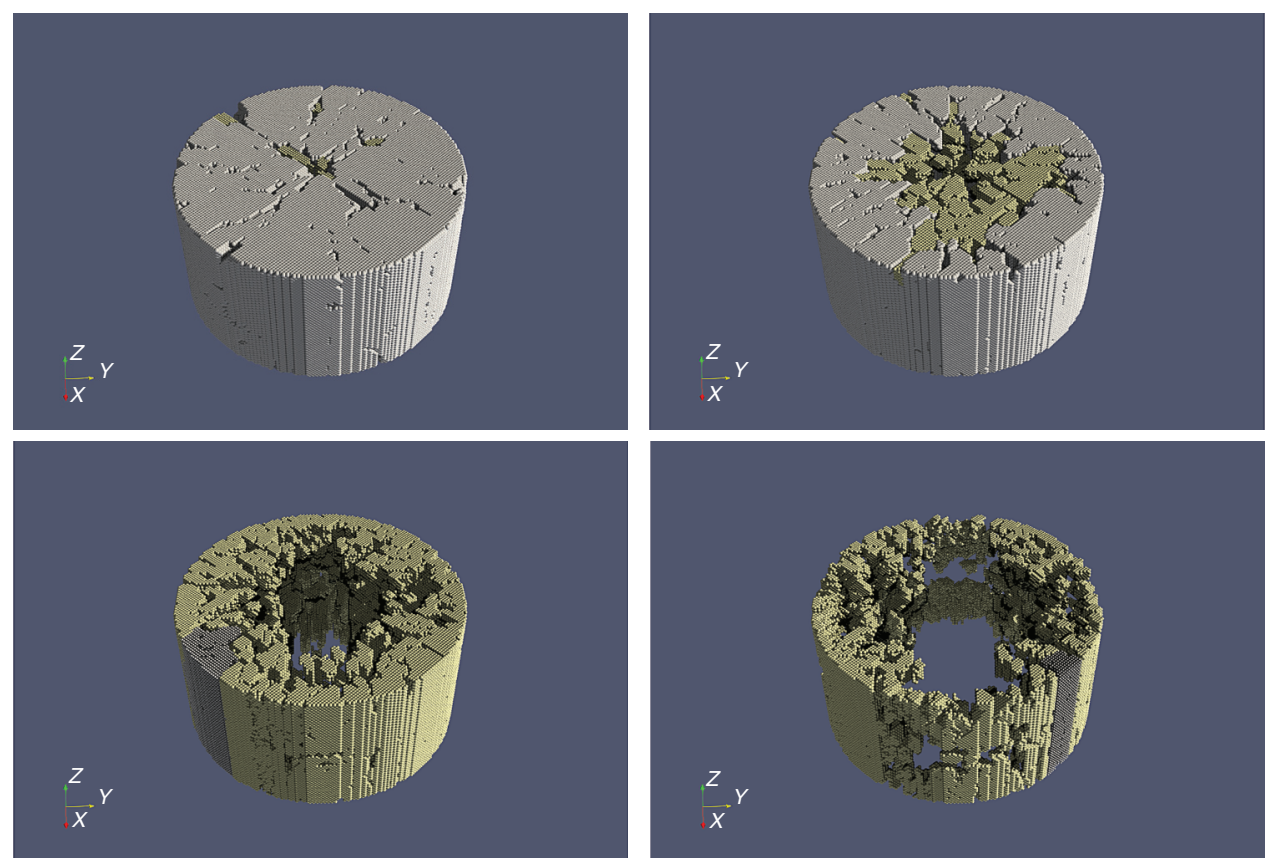

FIG. 1. The numerically computed fragmented cylinders, with $P_{\text {peak }}=35,60,80$, and $160 \mathrm{MPa}$, top left to bottom right, respectively. Reconstructions with fragments larger than $s=100$ are shown. The largest intact fragment is shown in gray. Fragments containing more than 100 DEM particles are shown in yellow. Smaller fragments are omitted. The DEM-particle radius, $r_{\text {grain }}=$ $3 \mathrm{~mm}$. experimental MPF also deviates from the GGS function. This part contains the boulders, and in Fig. 2(a) an exponential function for $n_{b}(s)$ is used.

The much shorter curve in Fig. 2(a) consists of the numerical MPF and the corresponding fit to the theoretical MPF. The rather striking difference between the experimental and numerical MPFs has the rather trivial origin that the mortar grains are typically of size $r_{\text {grain }} \sim 0.1 \mathrm{~mm}$, while in the simulations $r_{\text {grain }} \sim 3 \mathrm{~mm}$ is used. Figure 2(b) displays a more useful comparison: as this figure demonstrates, the crushing part of $n(s)$ extends to the kink at about 20-30 grains for both the experimental and the numerical data. Since the grain size in the numerical model is $r_{\text {grain }}=3 \mathrm{~mm}$, and in the experimental model $r_{\text {grain }} \sim 0.1 \mathrm{~mm}$, this means that the mass fraction for crushing is much larger for the numerical data, and it indicates that numbers of grains rather than fragment mass govern crushing.

The data points corresponding to the largest fragments (approximately $C_{3}$ ) in Fig. 2(b) are approximately $10^{4}$ for the numerical data and approximately $10^{8}$ for the experimental [there are so few boulders that $n(s)$ cannot be determined and they are therefore left out of Fig. 2(b)]. This reflects the scaling $C_{3} \propto r_{\text {grain }}^{-3}$ quite well, indicating
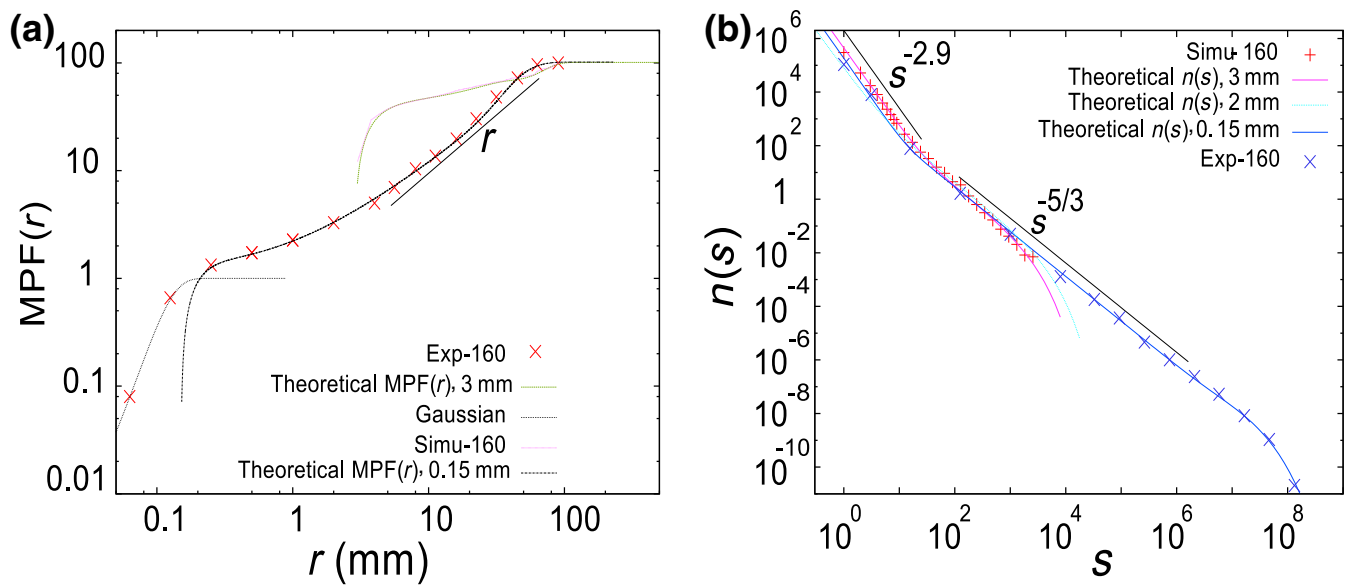

FIG. 2. Experimentally and numerically obtained (a) MPFs and (b) values of $n(s)$ for $P_{\text {peak }} \approx 160$ MPa. The experimental (Exp$160)$ and numerical (Simu-160) data are fitted with the theoretical MPF. In (a) the GGS $(m=1)$ function (MPF $\propto r)$ is displayed for comparison, and the grain-size distribution for the fines tail of the experimental MPF is compared to a Gaussian function (grains in the size range $r \sim 0.1 \mathrm{~mm}$ ). In (b), the power laws for crushing and branching-merging are displayed for comparison. The numerical results are for $r_{\text {grain }}=2$ and $3 \mathrm{~mm}$. The large-fragment cut-off for the distributions (approximately $C_{3}$ ) scales as $C_{3} \propto r_{\text {grain }}^{-3}$. 
(a)

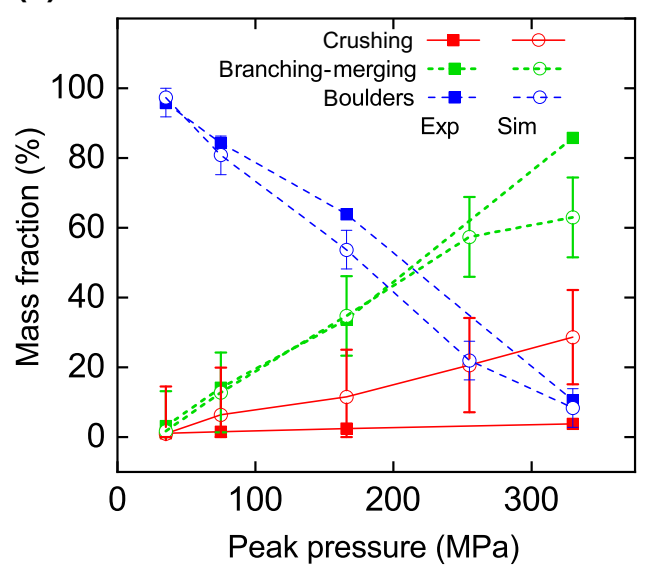

(b)

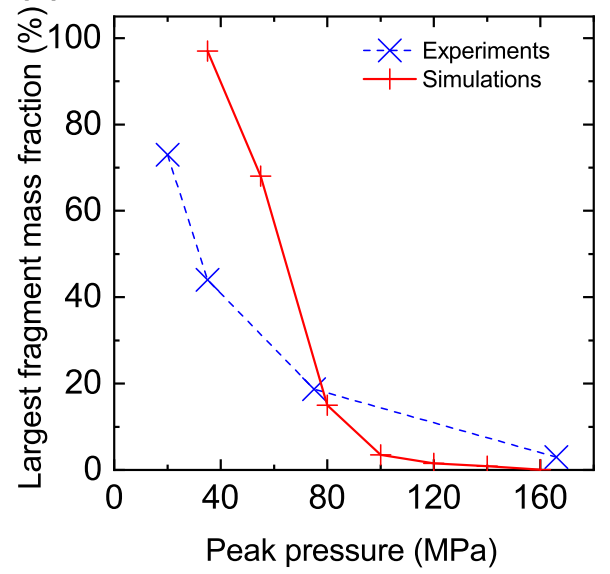

FIG. 3. (a) The crushing, branching-merging, and boulder mass fractions as functions of $P_{\text {peak }}$ for numerical simulations with $r_{\text {grain }}=$ $3 \mathrm{~mm}$ and $P_{\text {post }}=0.004 P_{\text {peak }}$, and experiments with a stiff cylinder confinement. Filled symbols denote the experimental data and unfilled symbols show the simulation data. The estimated errors of the numerical results compared with the experimental data are illustrated by error bars. (b) The mass fraction of the largest fragment as a function of $P_{\text {peak }}$ for simulations with $P_{\text {post }}=0.06 P_{\text {peak }}$ and experiments with a looser confinement: continuous line, simulation; broken line, experiments.

that while number of grains are important for the mass fraction of the crushing fragments, this is not so for the larger fragments. To confirm this, we also compute $n(s)$ for $r_{\text {grain }}=2 \mathrm{~mm}$. The best fit to this data by the theoretical $n(s)$ is also displayed in Fig. 2(b). As is evident, the data in this case follow the data for $r_{\text {grain }}=3$ $\mathrm{mm}$, except that $C_{3}$ moves to a larger value of $s$ by an amount roughly consistent with the expected scaling. Consequently, as the observed scaling $C_{3} \propto r_{\text {grain }}^{-3}$ entails, the largest fragments formed by branching-merging have sizes that are independent of $r_{\text {grain }}$.

Both Eqs. (1) and (2) can be used to define mass fractions of fragments formed by crushing, branchingmerging, and boulders. It is an interesting exercise to plot (a)

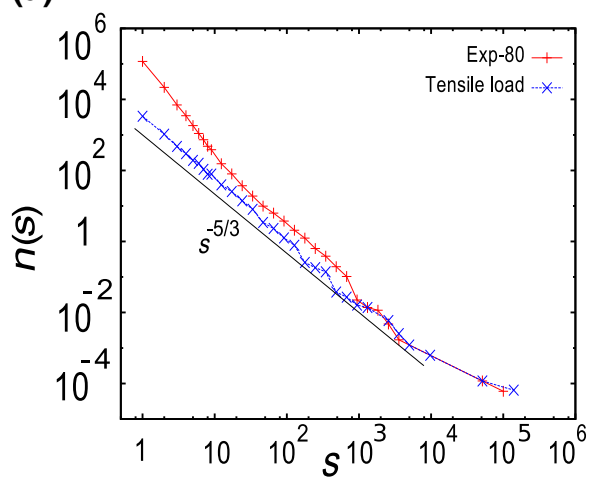

(c)

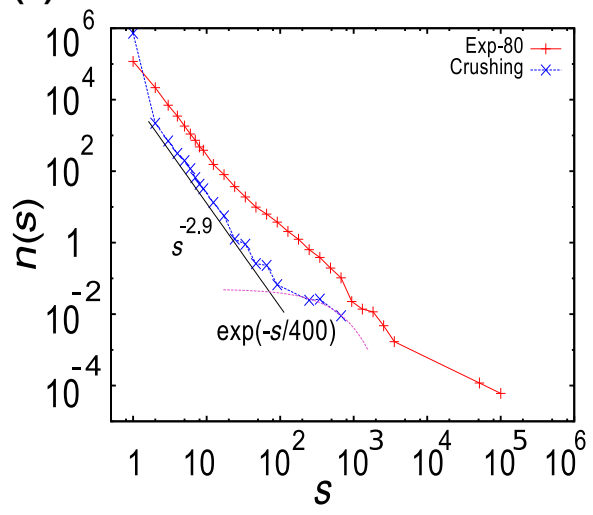

(b)

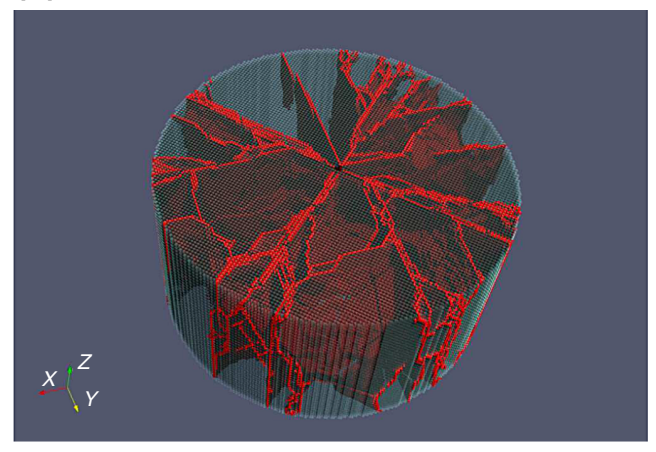

(d)

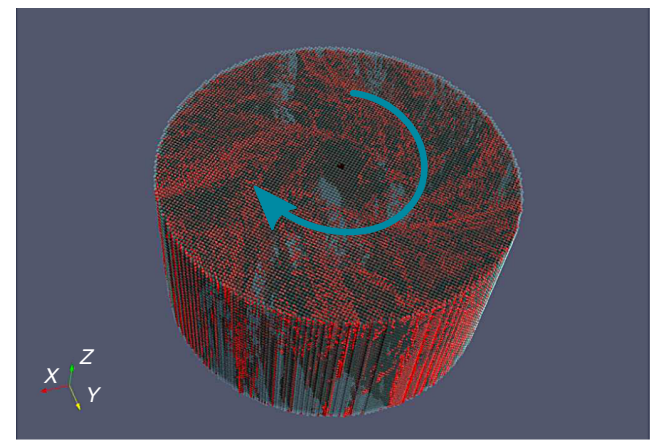

FIG. 4. (a) $n(s)$ for inflation fragmentation compared to the branching-merging power law. (b) Crack patterns formed during inflation. (c) $n(s)$ for grinding fragmentation compared to the crushing power law. (d) Crack patterns formed during grinding: the arrow shows the direction of rotation. The blasting $n(s)$ of $P_{\text {peak }}=$ $80 \mathrm{MPa}$ is displayed for comparison, and an exponential function indicates boulders shown in (c). 
these mass fractions from the fitted functions as a function of $P_{\text {peak }}$ for the numerical and experimental data. Another useful plot is the mass fraction of the largest fragment as a function of $P_{\text {peak }}$.

Figure 3(a) displays the mass fractions for the three categories as functions of $P_{\text {peak }}$, for simulations with $P_{\text {post }}=0.004 P_{\text {peak }}$ and experiments with a stiff confinement [12]. The numerical data $\left(r_{\text {grain }}=3 \mathrm{~mm}\right)$ again confirm the significantly larger mass fraction for crushing for the larger-grain-size numerical data as compared to the experiments [Fig. 3(a)]. For the other categories, the trend is, as expected, that the mass fraction of the boulders decreases significantly with $P_{\text {peak }}$, while those of the smaller fragments created by branching-merging and crushing increase, also as expected. It is obvious that the numerical and experimental data match each other very well, apart from the expected deviations due to differences in $r_{\text {grain }}$, which also explain the slight difference in the branching-merging mass fraction for the highest $P_{\text {peak }}$, at which the crushing mass fraction grows large enough to begin depleting the branching-merging fraction. The estimated errors of the numerical results are measured (using the standard error of estimate) and illustrated by the error bars. The value for crushing is $13.5 \%$ and that for branching-merging is $11.4 \%$, while the value for the boulders is $5.37 \%$.

Figure 3(b) displays the mass fraction of the largest fragment in the simulations compared to the difference in the mass-passing fraction between the largest and secondlargest mesh-size sieves, which can be used as a proxy for the largest fragment. These results are for loose experimental confinement and simulations with $P_{\text {post }}=0.06 P_{\text {peak }}$. Figure 3(b) demonstrates that a value of $P_{\text {peak }} \sim 60-80$ $\mathrm{MPa}$ or larger is needed to reach the breakage threshold of the cylinder. This corresponds to the damagefragmentation transition [32,33]. At smaller $P_{\text {peak }}$, the mass fraction of the largest "fragment" is approximately 1.

To further demonstrate the difference between tensile and compressive fragmentation, we apply two artificial loading conditions that have no direct experimental counterparts. These two loading conditions are chosen to either maximize the tensile loading and minimize the compressive crushing or vice versa. For tensile loading, we apply a force on each DEM particle that increases linearly with time in the outward radial direction, a so-called inflation. For crushing, we apply a similar load on each particle as a compression along the cylindrical axis, as well as a tangential torsion force acting clockwise around the axis of the cylinder; i.e., we choose loading conditions that mimic either a slow "inflation" or a traditional grinding motion.

The results of this exercise are displayed in Fig. 4. Figure 4(a) shows $n(s)$ for the tensile loading condition and, for comparison, the corresponding function for blasting at $P_{\text {peak }}=80 \mathrm{MPa}$ and the branching-merging powerlaw function $s^{-5 / 3}$. This figure clearly demonstrates that, in this case, $n(s)$ consists of branching-merging fragments and boulders, while crushing fragments are absent. The cracks formed during inflation are displayed in Fig. 4(b). Here, the branching and merging of cracks that form small fragments in fracture zones along the major crack paths are clearly visible. Also, the large boulders between the cracks are easy to detect. This crack pattern largely mimics what can be observed in the experiments, except for the crushing zones near the borehole that can be seen in Fig. 1, for which blasting is applied.

This particular case of inflation fragmentation produces an FSD with ten boulders. The largest one contains $20 \%$ of the mass and the smallest $1.3 \%$ of the mass. Together, they make up $87 \%$ of the mass. The remaining mass is contained in the branching-merging fragments. Also for these, the majority of the mass is contained in the larger fragments. This is easily demonstrated by the integral $\int s^{-5 / 3} s d s$, which represents the total mass, and which gets its major contribution from large values of $s$.

Figures 4(c) and 4(d) show the corresponding results for the grinding-type loading condition. Figure 4(c) shows that $n(s)$ follows the crushing power law $n(s) \propto s^{-2.9}$ for fragments of a size up to about $s \sim 100$. It is worthwhile noting that the number of fragments piles up at $s=1$, indicating that the grinding process attempts to break even these small fragments - which, however, is not allowed in the numerical model. A few boulders that are described well by an exponential function can also be detected.

The crack pattern in Fig. 4(d) show rather obvious traces of the grinding process, and it is distinctly different from the tensile pattern in Fig. 4(b). The grinding process proceeds so that at first a few shear cracks are formed which determine the boulders, and thereafter the grinding process proceeds by crushing fragments within shear zones formed along the shear cracks [13].

\section{SUMMARY AND CONCLUSION}

In summary, the results in this paper clearly demonstrate that blasting-fragmentation FSDs are composed of three parts, all of which can be described separately by universal fragmentation mechanisms. The fines, or the smallest dustlike particles, arise almost exclusively as a result of compressive-shear fragmentation or crushing. Crushing consumes a lot energy as the density of fracture surfaces increases considerably in regions with very fine fragmentation. The grain-size distribution of the material seems to influence crushing significantly, in contrast to the larger fragments. That is, the mass fraction of the crushing fines decreases with smaller grains, at least for the particular fragmentation-process boundary conditions used here. Thus DEM modeling will probably tend to overestimate the amount of crushed material produced by blasting.

Fragments larger than fines are formed as a result of tensile-crack propagation. Tensile cracks branch and 
merge to form smaller fragments, and the tensile cracks delineate the largest fragments, called boulders.

Our results indicate two possible strategies for addressing the fines problem. (1) As the fraction of fines increases monotonically with $P_{\text {peak }}$ and a minimum $P_{\text {peak }}$ is required to reach the breakage threshold, the blasting process should be designed with a minimum load to reach this threshold, and with a suitable geometrical proximity of applied charges to limit the resulting boulder size. (2) The blasting itself should be designed so that it minimizes compressive shear and maximizes tensile load. In full-scale blasting rounds with a sequence of delayed holes, alternative (1) would have to include a consideration of the effect of the jointing of the rock mass. The delay sequence itself makes it possible to extend alternative (2) to include consideration of the interaction of tensile cracks from one blasthole with the waves emanating from the next. When computer capacity has grown sufficiently, a code such as HiDEM could become a valuable tool in choosing the right combination of blast parameters at full scale.

\section{ACKNOWLEDGMENTS}

This project is funded by the Austrian Science Fund (FWF) Grant No. P27594-N269 and has been performed under the Project HPC-EUROPA3 (Grant No. INFRAIA2016-1-730897), with the support of the EC Research Innovation Action under the $\mathrm{H} 2020$ program. In particular, we gratefully acknowledge the support of the CSC - IT Center for Science for the computer resources and technical support provided.

[1] F. Ouchterlony, Report project P2000-10: Energy optimisation during comminution. Stockholm: Swedish Min. Res. Org. MinFo.

[2] P. Moser, in Proceedings of EFEE 2nd World Conference on Explosives and Blasting Technique, 2003, edited by R. Holmberg (Rotterdam, Balkema, 2003), p. 335.

[3] P. Moser, in Proceedings of 3rd EFEE World Conference on Explosives and Blasting, edited by R. Holmberg (Brighton, UK, 2005), p. 567.

[4] J. A. Herbst and W. T. Pate, in Proceeding of Mine to Mill Conference, Brisbane, 1998 (AusIMM, Carlton, 1998), p. 243.

[5] D. Thornton, S. S. Kanchibotla, and I. Brunton, in Proceedings of Explo 2001 Conference, 2001, edited by A. Marton (AusIMM, Carlton, 2001), p. 197.

[6] N. Djordjevic, in Proceedings of 6th International Symposium for Rock Fragmentation by Blasting, Johannesburg, 1999, edited by The South African Institute of Mining and Metallurgy (SAIMM, Johannesburg, 1999), p. 213.

[7] N. Djordjevic, Origin of blast-induced fines, Min. Technol. 111, 143 (2002).

[8] I. Onederra, S. Esen, and A. Jankovic, Estimation of fines generated by blasting - applications for the mining and quarrying industries, Min. Technol. 113, 237 (2004).
[9] See the Supplemental Material at http://link.aps.org/supple mental/10.1103/PhysRevApplied.10.034001 for a schematic representation of the star-shaped crushed-zone model, Figure 1 and the detailed project application.

[10] V. Svahn, Lic. thesis, Chalmers University of Technology, 2003.

[11] A. Iravani, I. Kukolj, F. Ouchterlony, T. Antretter, and J. Åström, in Proceedings of 12th International Symposium for Rock Fragmentation by Blasting, 2018, edited by H. Schunnesson \& D. Johansson (Luleå University of Technology, Luleå, 2018), p. 597.

[12] D. Johansson, Lic. thesis, Luleå University of Technology, 2008.

[13] J. A. Åström, Statistical models of brittle fragmentation, Adv. Phys. 55, 247 (2006).

[14] J. A. Åström, R. P. Linna, J. Timonen, P. F. Mœller, and L. Oddershede, Exponential and power-law mass distribution in brittle fragmentation, Phys. Rev. E 70, 026104 (2004).

[15] F. Ouchterlony and P. Moser, in Proceedings of the 10th International Symposium for Rock Fragmentation by Blasting, edited by K. Singh Pradeep \& S. Amalendu (CRC Press/Balkema, Boca Raton, 2012), p. 65.

[16] P. Moser, N. Cheimanoff, R. Ortiz, and R. Hochholdinger, in Proceedings of the EFEE 1st World Conference of Explosives and Blasting Technique, Rotterdam, 2000, edited by R. Holmberg (A.A. Balkema, Rotterdam, 2000), p. 165.

[17] FWF project P27594-N29; see detailed project application at [9].

[18] I. Kukolj, A. Iravani, F. Ouchterlony, C. Weiss, and J. Lubensky, in Proceedings of 12th International Symposium for Rock Fragmentation by Blasting, Luleå, Sweden, 2018, edited by H. Schunnesson \& D. Johansson (Luleå University of Technology, Luleå, 2018), p. 483

[19] J. A. Åström, T. I. Riikilä, T. Tallinen, T. Zwinger, D. Benn, J. C. Moore, and J. Timonen, A particle based simulation model for glacier dynamics, Cryosphere 7, 1591 (2013).

[20] S. Nie, Swedish Rock Engineering Research Foundation SveBeFo Report No. 42.

[21] P. Kekäläinen, J. A. Åström, and J. Timonen, Solution for the fragmentation-size distribution in a crack-branching model of fragmentation, Phys. Rev. E 76, 026112 (2007).

[22] T. I. Riikilä, T. Tallinen, J. A. Åström, and J. Timonen, A discrete-element model for viscoelastic deformation and fracture of glacial ice, Comput. Phys. Commun. 195, 14 (2015).

[23] R. Ouyed, J. Staff, and P. Jaikumar, Quark-novae in lowmass X-ray binaries with massive neutron stars: A universal model for short-hard gamma-ray bursts, Astrophys. J. 729, 60 (2011).

[24] A. Stern, A. Adcroft, and O. Sergienko, The effects of Antarctic iceberg calving-size distribution in a global climate model, J. Geophys. Res.: Oceans 121, 5773 (2016).

[25] D. Sornette, Critical Phenomena in Natural Sciences: Chaos, Fractals, Selforganization and Disorder: Concepts and Tools (Springer Science and Business Media, Berlin, 2006).

[26] A. Billi, On the extent of size range and power law scaling for particles of natural carbonate fault cores, J. Struct. Geol. 29, 1512 (2007).

[27] J. F. Kok, A scaling theory for the size distribution of emitted dust aerosols suggests climate models 
underestimate the size of the global dust cycle, PNAS 108, 1016 (2011).

[28] R. Mahmoodi Baram, H. J. Herrmann, and N. Rivier, Space-Filling Bearings in Three Dimensions, Phys. Rev. Lett. 92, 044301 (2004).

[29] J. A. Åström and J. Timonen, Spontaneous formation of densely packed shear bands of rotating fragments, Eur. Phys. J. E 35, 40 (2012).

[30] D. E. Grady and M. E. Kipp, Geometric statistics and dynamic fragmentation, J. Appl. Phys. 58, 1210 (1985).

[31] B. A. Wills and J. Finch, Wills' Mineral Processing Technology: An Introduction to the Practical Aspects of Ore Treatment and Mineral Recovery (ButterworthHeinemann, Oxford, 2015).

[32] F. Kun and H. J. Herrmann, Transition from damage to fragmentation in collision of solids, Phys. Rev. E 59, 2623 (1999).

[33] J. Åström, M. Kellomäki, and J. Timonen, Dynamic fragmentation of a two-dimensional brittle material with quenched disorder, Phys. Rev. E 55, 4757 (1997).

[34] S. Esen, I. Onederra, and H. A. Bilgin, Modelling the size of the crushed zone around a blasthole, Int. J. Rock Mech. Min. Sci. 40, 485 (2003).

[35] F. Ouchterlony, The Swebrec function: Linking fragmentation by blasting and crushing, Min. Technol. 114, 29 (2005).

[36] F. Ouchterlony, in Proceedings of 9th International Symposium on Rock Fragmentation by Blasting, Leiden, 2009, edited by J. A. Sanchidrián (CRC Press / Taylor \& Francis Group, London, 2009), p. 3.

[37] F. Ouchterlony, U. Nyberg, P. Bergman, and S. Esen, in Proceedings of 4th EFEE World Conference Explosives and Blasting Technique, Vienna, 2007, edited by P. Moser (European Federation of Explosives Engineers, UK, 2007), p. 47.

[38] A. Miklautsch, Dipl. thesis, Montanuniversität Leoben, Austria, 2002.

[39] G. Reichholf, PhD thesis, Montanuniversität Leoben, Austria, 2003.

[40] P. Moser, M. Olsson, F. Ouchterlony, and A. Grasedieck, in Proceedings of EFEE 2nd World Conference on Explosives and Blasting Technique, 2003, edited by R. Holmberg (Roterdam, Balkema, 2003), p. 449.

[41] H. C. Grimshaw, in Proceedings of Mechanical Properties of Non-Metallic Materials, 1985, edited by W. H. Walton (Butterworths, London, 1985), p. 380.

[42] F. Ouchterlony, U. Nyberg, M. Olsson, I. Bergqvist, L. Granlund, and H. Grind, in Proceedings of EFEE 2nd World Conference Explosives and Blasting Technique, 2003, edited by R. Holmberg (Rotterdam, Balkema, 2003), p. 193.

[43] J. A. Sanchidrián and L. M. López, in Proceedings of EFEE 2nd World Conference Explosives and Blasting Technique, 2003, edited by R. Holmberg (Rotterdam, Balkema, 2003), p. 357.

[44] J. A. Sanchidrián, P. Segarra, F. Ouchterlony, and L. M. López, On the accuracy of fragment size measurement by image analysis in combination with some distribution functions, Rock. Mech. Rock. Eng. 42, 95 (2009).
[45] J. A. Sanchidrián, P. Segarra, L. M. López, and F. Ouchterlony, in Proceedings of 9th International Symposium on Rock Fragmentation by Blasting, 2009, edited by J. A. Sanchidrián (CRC Press / Taylor \& Francis Group, Leiden, 2009), p. 239.

[46] J. A. Sanchidrián, F. Ouchterlony, P. Moser, P. Segarra, and L. M. López, Performance of some distributions to describe rock fragmentation data, Int. J. Rock Mech. Min. Sci. 53, 18 (2012).

[47] J. J. Gilvarry, Fracture of brittle solids. I. Distribution function for fragment size in single fracture (theoretical), J. Appl. Phys. 32, 391 (1961).

[48] H. J. Steiner, in Proceedings of 17th International Mining Processing Congress, Dresden, 1991 (Bergakademie Freiberg, Freiberg, 1991), p. 177.

[49] F. Ouchterlony and P. Moser, in Proceedings of 8th International Symposium on Rock Fragmentation by Blasting, Chile, 2006, edited by S. A. Editec (Ediarte S.A., Chile, 2006), p. 207.

[50] S. P. Michaux, Sub-populations and patterns in blast induced fine fragmentation, Miner. Eng. 22, 576 (2009).

[51] Z. X. Zhang, S. Q. Kou, L. G. Jiang, and P.-A. Lindqvist, Effects of loading rate on rock fracture: Fracture characteristics and energy partitioning, Int. J. Rock Mech. Min. Sci. 37, 745 (2000).

[52] P. K. V. V. Nukala, S. Zapperi, M. J. Alava, and S. Simunović, Crack roughness in the two-dimensional random threshold beam model, Phys. Rev. E 78, 046105 (2008).

[53] S. Morel, E. Bouchaud, J. Schmittbuhl, and G. Valentin, R-curve behavior and roughness development of fracture surfaces, Int. J. Fracture 114, 307 (2002).

[54] M. H. B. Nasseri, G. Grasselli, and B. Mohanty, Fracture toughness and fracture roughness in anisotropic granitic rocks, Rock. Mech. Rock. Eng. 43, 403 (2010).

[55] A. Grasedieck, PhD thesis, Montanuniversität Leoben, Austria, 2006.

[56] D. Johansson, PhD thesis, Luleå University of Technology, Sweden, 2011.

[57] D. E. Grady and M. E. Kipp, in High-Pressure Shock Compression of Solids. High-Pressure Shock Compression of Condensed Matter, edited by J. R. Asay \& M. Shahinpoor (Springer, New York, 1993).

[58] J.-T. Wang, Tailored pulse loading method, Sci. China A 32, 120 (1989).

[59] F. Dai, PhD thesis, University of Toronto, 2010.

[60] M. H. B. Nasseri, F. Rezanezhad, and R. P. Young, Analysis of fracture damage zone in anisotropic granitic rock using 3D X-ray CT scanning techniques, Int. J. Fracture 168, 1 (2011).

[61] A. Scott, S. Michaux, and I. Onederra, in Proceedings of 9th International Symposium on Rock Fragmentation by Blasting, 2009, edited by J. A. Sanchidrián (CRC Press / Taylor \& Francis Group, Leiden, 2009), p. 663.

[62] Z. P. Bažant, J.-L. Le, F. R. Greening, and D. B. Benson, What did and did not cause collapse of WTC twin towers in New York, ASCE J. Eng. Mech. 134, 892 (2008). 